Psychology in The Netherlands, The Nijmegen Papers, edited by M. Brouwer, J. van Ginneken, A. Hagendoorn, and J.D. Meloen. Amsterdam: Mola Russa.

Meloen, J.D., L. Hagendoorn, Q. Raaijmakers, and L. Visser, L 1988. "Authoritarianism and the Revival of Political Racism: Reassessments in The Netherlands of the Reliability and Validity of the Concept of Authoritarianism by Adorno et al." Political Psychology 9 ( 3): 413-429.

Meloen, J.D. 1991. "The Fortieth Anniversary of "The Authoritarian Personality'." Politics and the Individual 1(1) 119-127.

Meloen, J.D. 1993. "The F Scale as a Predictor of Fascism: An Overview of 40 Years of Authoritarianism Research." Pp. 4769 in Strength and Weakness: The Authoritarian Personality Today, edited by W.F. Stone, G. Lederer, and R. Christie. New York: Springer Verlag.

Meloen J.D., G. Van der Linden, H. de Witte. 1996. "A Test of the Approaches of Adorno et al., Lederer and Altemeyer of Authoritarianism in Belgian Flanders: A Research Note." Political Psychology 17(4): 643-656.

Montgomery, R.L., S.W. Hinkle, and R.F. Enzie. 1976. "Arbitrary Norms and Social Change in High and Low Authoritarian Societies." Journal of Personality and Social Psychology 33(6): 698-708.

Sales, S.M. 1972. "Economic Threat as a Determinant of Conversion Rates in Authoritarian and Non-Authoritarian Churches." Journal of Personality and Social Psychology 23(3): $420-428$.

Sales, S.M. 1973. "Threat as a Factor in Authoritarianism: An Analysis of Archival Data." Journal of Personality and Social Psychology 28(1): 44-57.

Schreiber, E.M. 1978. "Education and Change in American Opinions on a Woman for President." Public Opinion Quarterly 42: 183-198.

Stone, W.F., G. Lederer, and R. Christie, editors. 1993. Strength and Weakness: The Authoritarian Personality Today. New York: Springer Verlag.

U.S. Historical Statistics. Historical Abstracts of the U.S.A., Colonial Times to 1970, Volume I and II. Department of Commerce, Bicentennial Edition.

U.S. Statistical Abstracts. 1970-1981. Statistical Abstracts of the U.S.A. Yearbooks.

Winter, D.G. 1996. Personality: Analysis and Interpretation of Lives. New York: McGraw-Hill.

\section{ATTACHMENT EXPERIENCES AND AGGRESSION AGAINST MINORITIES ${ }^{\prime}$}

\author{
Christel Hopf \\ Institut für Sozialu'issenschaften \\ Universität Hildesheim
}

Social Thought and Research, 1998. Vol. 21, 1-2

This article is the revised version of a lecture given in October 1996 at the 28th Congress of the German Society for Sociology in Dresden. See also the German text in Stefan Hrad'l (ed.), Verhandlungen des 28. Kongresses der Deutschen Gesellschaft für Soziologie in Dresden (1997).

\section{Introduction}

In recent years, the most striking and politically spectacular aggressive acts against minorities committed in Germany have been directed against ethnic minorities and political asylum-seekers. In this article, I will attempt a social-psychological analysis of this particular kind of aggression by combining insights from attachment research with authoritarianism research.

Aggression against minorities can be analyzed on a number of different levels:

-- the level of society: this level involves aggression that is firmly embedded in the political culture. Such aggression can also find official sanction in laws, administrative regulations, and directives for how state employees are to act. The most obvious and extreme example of this in Germany is the array of discriminatory regulations and legislation used to confine. ostracize, and destroy the Jewish population during the National Socialist period.

\footnotetext{
Translation: Carol Scherer
} 
- the level of formal organizations: such analyses examine organizations - professional associations, political parties, and the like -- whose programs assign a significant role to anti-Semitic ideologies or those hostile to foreigners, and call explicitly for aggressive action against specific groups.

- the level of groups: at this level one can, for example, investigate a range of group processes leading to violent acts against foreigners. Specific group cultures with xenophobic, hostile tendencies constitute another area for this kind of analysis.

- the level of individual persons: such analyses focus on the individual willingness to commit aggressive acts against ethnic minorities. These actions can find expression in verbal form or violent action. they can be aimed directly against the despised groups or harm them by indirect means. The most frequent form of such indirect aggression are the everyday discussions in the family, the work-place, or neighborhood bar, where Africans, Vietnamese, or "asylum seekers" are used to explain any number of social ills - criminality, applying for political asylum under false pretexts, "sucking dry" or exploiting the social welfare system (on the concept of indirect aggression see Björkquist \& Niemelä 1992).

It is this last level - the level of individual actions and potential actions -- that stands at the center of this article. I plan to explore the social and psychological conditions behind an individual's willingness to harm -- directly or indirectly - ethnic minorities in German society.

In Germany, the issue of individual susceptibility to aggression against minorities has taken on new significance in the lively and often bitter controversy surrounding the work of Daniel Goldhagen (1996). Particularly compelling is the question whether anti-Semitic tendencies in nineteenth- and twentieth-century Germany were particularly aggressive and annihilatory, thus forging a critical foundation, anchored in potential individual action, for the persecution and murder of the European Jews.

Both today and in the past, German fascism has repeatedly prompted questions about the structural and individual conditions of prejudice, as well as the readiness to use violence. One famous example of a study that was shaped by the confrontation with National Socialism and anti-Semitism in Germany is the investigation into the "authoritarian personality," conducted during the 1940s in the United States (Adorno/Frenkel-Brunswik/Levinson/Sanford 1950). The research team of social scientists was explicitly concerned with the level of individual prejudice and action. They explored the social and psychological foundations of ethnocentric tendencies. including anti-Semitism. Their primary interest was in potentially fascist individuals, people who would not explicitly designate themselves as such and who were not already organized in fascist groups, but who nonetheless were susceptible to fascist propaganda.

The studies in The Authoritarian Personality constitute the first major empirical investigation on aggression against minorities as it relates to inner-familial socialization and attachment experiences. In what follows I will introduce the socialization and relationship theories developed in the AP investigations, and address the widespread criticism of these theories. In the third part of the article, I attempt to draw some conclusions from the critical reception of the AP studies by turning to a discussion of recent empirical studies on how aggression against minorities relates to attachment experiences, particularly how individuals deal with such experiences subjectively. My concluding comments explore the development of a more complex model for political socialization.

\section{How attachment and socialization experiences relate to aggression -- the approach in The Authoritarian Personality}

Central features of the 1940s "authoritarian personality" studies are the ethnocentrism concept and authoritarianism concept. The concept of ethnocentrism, first developed by the American sociologist Sumner in 1906, involves a coupling of cognitive and affective attitudes. Here the ingroup, such as one's own nation or religion, is grossly overvalued, while outgroups - - ethnic, religious, or other minorities - are disparaged and despised. ${ }^{2}$

${ }^{2}$ See in particular chapter IV ("The study of ethnocentric ideology") in The Authoritarian Personality written by Levinson. It is interesting to note that, like other important chapters in the original, almost one thousand-page long Authoritarian Personality, this chapter was not included in the German translation from 1973 (see Adorno 1973). Unfortunately the same holds for the chapters (IX to XIII) written by Else Frenkel-Brunswik, the results of which are particularly important for authoritarianism research (see below). 
Such ethnocentrism is, seen from the AP approach, especially marked in people who fit the "authoritarian" type. They stoop to those above them, venerate authorities in the ingroup (authoritarian subordination), trample upon the weaker and minorities, indeed feel themselves morally entitled to do so (authoritarian aggression), and adhere to accepted conventional behavior and external appearances (on this point and other features of the authoritarian syndrome, see in particular the chapter on the F scale in Adorno et al. 1969, $222 \mathrm{ff}$.).

In their interpretation of ethnocentric and authoritarian tendencies in individuals, the AP research team took up theoretical traditions from the Frankfurt School of Social Research. The investigations in The Authoritarian Personality echo a key assumption in the Studies on Authority and Family from 1936: decisive for an individual's ability to resist pressure from authorities is how authority is exercised within the family and the character of inner-familial relationships. Like Erich Fromm in his psychoanalytic explanations of the sadomasochistic character, moreover, they saw a close relationship between an individual's compliance to authorities and his or her aggressivity towards minorities.

According to the theoretical approach in The Authoritarian Personality, ethnocentrism and authoritarianism take hold in individuals where:

-- on the one hand, a restrictive and punitive upbringing impedes the development of a strong ego and stabile internalized moral standards, and

- on the other hand, anger and criticism of the parents cannot be expressed. The suppressed aggression toward the parents and later other authorities - is displaced onto weaker individuals or groups.

Of the AP researchers, the Austrian-born psychologist Else Frenkel-Brunswik undertook the most intensive work into how parental styles of child-raising influence the social relationships between parents and children. Unfortunately these chapters of the original Authoritarian Personality were not translated and are little known in Germany (see note 2). Here FrenkelBrunswik evaluated qualitative interviews with both particularly anti-Semitic, ethnocentric individuals and particularly non-prejudiced individuals, providing critical insights into the structure of the authoritarian personality. She also offered more detailed analyses of the idealization tendencies of authoritarian individuals. Not only do they suppress criticism and aggression because they are afraid that their parents will react harshly, they are often not conscious of any reasons for such criticism. They are often not conscious of any in positive terms or even praise them effusively (see Adorno et al. 1969, 340 ff.). Contrary episodes, criticism, and hints of difficult experience with their parents seem to creep into the interviews against the intentions of the subjects, and undermine what is, at first glance, a positive image of their family life ${ }^{3}$

With its accentuation of the level of cognitive and affective representations, the idealization concept is highly relevant to the problem at hand. It is important to realize that not simply difficult personal experiences give rise to aggressivity toward the weaker, but rather the ways in which individuals deal with such problems. Does the individual acknowledge them as such, does he or she confront them critically, admit to feelings of hatred he or she confront them critically, admit to foelings of hations beneath a glorified shroud cast over the childhood?

At the same time, the idealization concept is too narrow. It At the same time, the idealization picture of how individuals deal with negative emotions towards their own parents. In the AP, the only distinction is between idealization and realistic representation. Other variants are neglected. Later studies have found, for example, an angry entanglement between parents and children and the deflection of criticism, where individuals admit to negative experiences but declare them to be emotionally irrelevant.

I would like to discuss this point in greater detail elsewhere in the article. First however I want to introduce and discuss the widespread criticism of basic assumptions in socialization theory from The Authoritarian Personality. At the core of this criticism stand doubts as to their empirical substance. The Canadian scholar Bob Altemeyer has expressed this concern with particular clarity (see Altemeyer 1988). In Germany, the

3 Interesting in this context are also the results of the TAT-Tests conducted with the subjects (on this point see chapter XIV of the AP, written by Betty Aron). These tests reveal strong aggression toward parent figures, not expressed in the standardized interview (see Adorno et al. 1969, 348). 
psychologist Detlef Oesterreich is perhaps the leading critic of the AP assumptions in socialization theory. Oesterreich Brunswik et al. theoretical assumptions of Adorno, Frenkelevidence he cites American and confirmed empirically. As Altemeyer's (1988) American and Canadian studies - such as 1993, 38-39). His own - along with his own work (see Oesterreich Oesterreich, not cold and cet only belies "a positive relationship between a attitude of parents to the child and its negative relationship (see," it suggests in fact a tendency to negative relationship (see Oesterreich 1993, 38). In other words Oesterreich concludes from his data that a cold and censorious upbringing style in parents can, in fact, promote the development of non-authoritarian tendencies in their children.

The idea that the assumptions in socialization theory from The Authoritarian Personality are not tenable was also adopted by some researchers from the former German Democratic Republic This idea strengthens their disinclination to confront GDR socialization critically -- socialization both in the family and the state-run establishments for child-care. Walter Friedrich (1993), for example, emphatically rejects the attempt to explain hostility to foreigners in the new (eastern) federal states against the background of GDR socialization and authoritarian structures. Indeed, Friedrich doubts that one can apply the concept of the "authoritarian personality" to former socialist societies at all.

More recent studies on young people from both the western and eastern federal states appear to lend support to the empirically-based doubts about the basic theoretical assumptions in The Authoritarian Personality. A 1993 representative survey of young men and women conducted in North Rhine-Westphalia, for example, turned up interesting results. In standardized interviews, the ethnocentric and violence-prone adolescents reported on conflicts and lack of harmony in their families; this was not the case among the young people who were "only" authoritarian and ethnocentric (see Litzmann- Krombholz 1994). The young men and women who did nor support violence, but were nonetheless nationalistic and authoritarian, described few problems or conflicts in their childhood and with their parents (see Utzmann-Krombholz 1994, 111-112). This group agreed to the following statements in roughly the same numbers as the average of the other respondents: "I had a happy childhood" (30 percent; average 32 percent), "my parents always supported me" (38 percent; average
37 percent), or "when I had problems, my parents were always there for me" (35 percent; average 35 percent). The nationalistic-authoritarian girls and young women in the survey presented a more favorable picture of their parents than did their male counterparts.

In another, comparative study of young people in East and West Germany, Klein-Allermann et al. (1995) present similar results. It is important to note that their questions about inner-familial relationships primarily address the present in statements such as "we feel safe in our family," or "we often squabble at home." Again we find a pattern in which unfavorable family experiences seem to figure as background to the willingness of young people to use violence, but play little role in tendencies to nationalisticauthoritarian and ethnocentric views.

On the surface, there do seem to be weighty arguments against key assumptions in socialization theory used in the AP studies. But we still need to ask if the empirically-based criticism of Adorno, Frenkel-Brunswik, et al. is convincing. Here I would like to summarize some concerns about its limitations.

1. When one looks at the work underpinning the criticism of the AP, neither the earlier studies (Altemeyer, Oesterreich, including the investigations summarized by Kirscht/Dillehay), nor the more recent studies mentioned above, involve longitudinal investigations beginning with data collection in childhood. In other words, these studies do not have information about early inner-familial experiences. Such experiences, if they are considered at all, are based on the retrospective memories of the study participants.

2. The retrospective appraisals of family relationships and the parental style of child-raising are collected solely with the help of standardized instruments. Qualitative interviews are not used. There is thus no room for the more complex interpretations of an individual's attachment and socialization experiences. Nor do we find the possibility to probe discrepancies between overall positive assessments of parents and concrete episodes and narratives. This shortcoming is particularly problematic because without the analysis of discrepancies and incoherences in the interview, one is not in the position to check whether or not the subjects tend to idealize their childhood and parents. 
3. In other words, the scholars who have criticized the approach from The Authoritarian Personality on empirical grounds are not in the position to check a pivotal thesis of this approach namely the idealization concept.

Because these scholars could not check the idealization thesis, they face difficult problems in interpreting and judging the results of their research. To cite an example from Oesterreich's standardized questionnaire on socialization at home (see Oesterreich 1974, 226 ff.), who will say yes to the following question: "Were you sometimes hit and didn't see why?" It could very well be that a more liberal person with a critical stance on his or her upbringing will answer yes; an authoritarian individual, who permits nothing negative in his or her parents, will answer no. Motto here: we deserved all the punishment we got.

Without additional information, what does a simple yes or no answer mean in this context? Taken at face value, nothing. We cannot draw conclusions about idealization tendencies or actual early upbringing. The same holds for related questions and answers about relationship and socialization experiences in the family, including those cited above. In concrete terms, what does it mean when a respondent checks off the statement on a standardized questionnaire that she could always turn to her parents when she had problems? Perhaps she has given a realistic summary of the child-parent relationship. But the same statement could also paint an embellished picture of her parents' willingness to bestow attention and care. Without additional information, how can we decide which interpretation is more apt?

In light of the methodological limitations on interpreting the responses in standardized studies about how attachment and socialization experiences are related to ethnocentrism, it seems wrong to maintain that the assumptions in socialization theory from The Authoritarian Personality have been refuted. One can disprove only those theses that are tested with appropriate and sound methods.

For all my efforts to critique the usual criticism of AP socialization theory, in no way do I intend to suggest the opposite conclusion - that the study's findings about socialization have been confirmed. I would confine myself to the comment that they have not been refuted, because the methods used thus far have not given appropriate consideration to central assumptions in The Authoritarian Personality and therefore could not test them in a methodologically responsible manner.

\section{Representation of childhood attachment and aggression against minorities}

The preceding critique of standardized procedures to study retrospective recollections of childhood points to two methodological correctives. First, the most appropriate way to check the socialization theory theses in The Authoritarian Personality is through longitudinal studies. Second, in the absence of long-term data, one needs, at the very least, to discuss such theses on the basis of qualitative interviews. Both points tackle the issue of understanding idealization tendencies, or other ways of deflecting difficult childhood experiences. Such tendencies can be described - if at all -- only on the basis of relatively open, qualitative interviews in which individuals are able to articulate both general assessments and concrete memories. In what follows, I would like to present some of the possibilities and results that have emerged from a recent qualitative examination of how young adults represent their childhood, and how this might relate to aggression against minorities.

In a series of qualitative investigations conducted over the last few years in the German federal state of Lower Saxony (one of the western states), our research team examined the inner-familial conditions of right-wing extremist and ethnocentric tendencies. ${ }^{4}$ Most of the young men and women who participated in the studies were trainees or apprentices in industry, artisanal crafts and professions, or administration and sales. Some tended toward more extreme right-wing attitudes while others tended to more liberal views. In case-study analyses, we examined not only theses of moral development in ethnocentric and non-ethnocentric men and women. but also theses about how such individuals deal with negative feelings and aggression toward their parents. In this process, we also took up the concept of parent idealization, but incorporated it

4 For more information on these studies see Hopf/Rieder' Sanden-Marcus/Schmidt 1995; Wernich 1996; Rieker 1996; Projektgruppe 1996; and chapters 2 and 3 in Hopf/Hopf 1997. 
into a more complex typology for how adults deal with their
experiences of attachment and conflict.

This typology was developed by Mary Main et al. in the field attachment research on the basis of "Adult Attachmen Interviews," semi-structured interviews with adults about their childhood (see Main'Goldwyn 1994, Main 1996). Based their analysis of interview transcripts, the researchers Based on the typology for describing how close relationships, developed a experiences of conflict and rejection, are dealt with in the family.

In the Main typology, three main categories emerge in adult attachment representation: 1. dismissing, 2. secure-autonomous, and 3. preoccupied-entangled.

1. All of the respondents described as dismissing tend to detach themselves in the way they think of and narrate their experiences. Attachment-related experiences and emotions remain "deactivated." This state is achieved in different ways. Some respondents combine idealizing, normalizing descriptions ability to remember. Others an insistence on rudimentary attachments when the interview problems or difficulties interview touches on topics involving problems or difficulties with their parents. Feelings of expressed in anger are left largely non-articulated, or are expressed in some cases as derogation, for example that it is not worthwhile wasting thoughts and feelings on such people.

2. Secure-autonomous respondents find it much easier to access their own relationships and emotions, as well as their own attachment history. They are able to speak openly and objectively about themselves. Even those who look back on history of insecure attachments are able to see and articulate them objectively, even if they express anger. They seem to value attachment as such and do not need to disparage relationships or emotions; nor do they remain caught in ongoing inner or actual conflicts with their parents.

3. A speaker's state of mind with respect to attachment is classified as preoccupied-entangled when a confused, angry, or passive preoccupation with attachment figures and experiences dominates the interview. It is hard for this group to regard their own relationship problems objectively and matter-of-factly, or to integrate such difficulties in a meaningful way into their understanding of self. What prevails instead is a passive preoccupation or an angry preoccupation - in both cases, it is an entanglement in relationships with the main attachment figures. They do not work through their anger; it is a constantly reproduced part of the relationship.

This typology is supplemented by a further pattern which complements these three main categories and is concerned with how individuals work through difficult experiences of loss or trauma.

In Main's typology, the "dismissing" pattern of adult attachment is particularly interesting in comparison to the idealization concept from the investigations in The Authoritarian Personality. It illustrates that the deflection of aggression against one's own parents can take place not only through consistent idealization, but also via a variant of dealing with attachment and conflict experiences in which the emotions are deflected. In the interview, difficult and painful experiences are described, but downplayed in terms of their emotional relevance (Main: "restricted in feeling"); this does not lead to open annoyance or anger with the parents. Because this "restricted in feeling" variant of a dismissing adult attachment representation turned up frequently in our interviews, I would like to explain it in more detail through the following example taken from our survey of young women.

In the course of the Adult Attachment Interview, one of the women ("Frauke") talked in vivid detail about her childhood anxieties: the fear of being alone at night, and the fear of her mother hitting her. Frauke tells that the mother beat her with a cooking-spoon when she romped too much in the apartment or "got on mother's nerves." In fear, she often tried to run away when her mother "came with the cooking-spoon," but to no avail.

In other words, the memory of her fear of being hit is present, but is pushed away, as the subsequent passages in the interview show. When asked about how her past relationship to her mother was, Frauke answered: "Was really a very good one. I could (--) always got everything really. (-) Of course getting a spanking is part of it, why wouldn't it when you're a smart aleck." The beatings were thus justified because they were deserved. The emotions of fear, documented in the description of running away from the "cooking-spoon," can be pushed away. Why should one get upset over experiences with 
punishment when it was apparently justified? There is thus, for Frauke, no reason to be angry with her mother. What dominates is the image of a very good upbringing. The fear of being alon -- described in lively detail somewhat earlier in the interview - is never mentioned again. The overall representation and the judgment of the relationship to mother instead take anothe turn: "Well I really liked to be with my mother. (- - somether longer pause). Well she really always tried, ah, to somewhat like where my everything always fair, divided didn't to be fair to both. Well she didn't play favorites or (-) didn't place one at a disadvantage or whatever. There really wasn't any of that. (-) It was always like that, always sharing both got the same thing. (--) Whether it was clothes to wear or (-) toys of some sort or (-) when we went somewhere. Well there was always the same for both."

The question, what there is to have, what she "gets" and what she wants to get, is a very important theme elsewhere in the interviews conducted with Frauke - in the Adult Attachment Interview, in the interview about her current relationships, and in the interview about her political leanings. At this point in the interview, when one, after the preceding recollections, might also have expected something about the emotional side of the mother-child relationship -- whether about the topic fear of the "cooking-spoon" or about the topic fear of being alone -, the material aspects of the relationship are shoved to the foreground. There were things -- "clothes," toys, and the like -- that one could get and what were divided up fairly by the mother. In reading the interview sections sketched here, one has the impression that by changing the topic to the dividing up of material goods in the family, it is easier to dismiss the emotional involvement. The material reference here strengthens the "restricted in feeling" (Main \& Goldwyn) variant of a dismissing adult attachment representation.

Among both the young men and the young women interviewed for this investigation, this "dismissing" variant of attachment representation is found more frequently than consistent idealization. Of the total of 52 interview subjects ( 28 men, 24 women), 31 were classified as "dismissing." Of this group, another 19 fit the emotionally-deprecating variant of dismissing, with no noteworthy difference between men and women.

We had, by the way, expected that men would tend more than women to the "dismissing" pattern for dealing with attachment and conflict experiences, while women would tend more toward entangled attachment representation. The investigation turned up something else. We did not observe these trends among the men and women in our study sample - how this might look with other samples, remains an open question. Indeed, our studies showed an even higher percentage of "dismissing" attachment representation among the women than among the men. In addition, the only "entangled" subjects turned out to be men. We would caution, however, against drawing the conclusion that the women in our study are less interested in relationships than the men. Almost all the women we interviewed aspire to lasting relationships and would like to marry and have children. The desire for a relationship, in other words, can easily go hand-in-hand with a deflection of attachment-related memories and emotions (on this point see also Silzer 1994).

Of the "entangled" subjects, those who cannot detach their thoughts and emotions from their attachment experiences, we were particularly interested in the angry-entangled individuals. While the subjects who fit the "dismissing" category display little annoyance or anger in relation to their parents or push aside such feelings, the angry-entangled subjects seem almost overwhelmed by their anger. One young man, for example, tells in the interview how he threatened his father with a baseball bat during a fit of rage and almost beat him up. He does not narrate this with a certain amount of distance or self-criticism, but talks himself into a renewed rage as he relates what happened.

Which concrete connections do we find between attachment representation and aggression against minorities? One of the most striking links is that very few subjects who fit the secure-autonomous category are markedly ethnocentric (2 of 11). In contrast, we find far more ethnocentric individuals in the dismissing category of attachment representation (18 of 31)..$^{5}$ It is also striking that the angry-entangled men are also ethnocentric. Indeed their ethnocentrism is expressed with particular violence. In other words, there are connections. Such links correspond, in part, to what one could expect from an expanded and modified idealization thesis. The emotions of annoyance and

5 For this point and what follows, I draw on current data evaluation from the survey of young women (Projektgruppe 1996) and on previous studies (Hopf et al. 1995, Wernich 1996, Rieker 1996). 
anger that are deflected and suppressed in the immediate family relationship can find expression in other contexts - vis-à-vis minorities. These are not however the only links. We also find the case of angry- or aggressive-entanglement. The individual allows to conflicts and affects, but cannot work through them and resolve them in a satisfactory way. Here we are not dealing with the suppression of aggression, but rather a very present aggressive agitation, with its point of departure in the parent-child relationship. Nor is this reaction confined to the parent-child constellation. It makes itself felt, even intensifies, in other social interactions.

What is important for the interpretation of potential ethnocentric behavior is not simply the submission to parental authority and the suppression of aggression, but something more general: how an individual deals with parental authority and aggression. Are we looking at an attempt to grapple with authorities in an objective, autonomous way? Does the individual integrate and work through aggressive impulses? Or do we find instead non-rational dealings with authorities and aggression, expressed in idealizing images of the individual's own attachment experiences, by pushing away such images, or in overwhelming, entangled aggression?

What comes to the foreground, in other words, are the individual's more or less rational dealings with his or her aggression. Precisely how an individual handles such emotions can help us understand the relationship between attachment representation and potential ethnocentric attitudes and actions. At the same time, we find other possible explanations which are, as I see it, not implausible.

One could, as the point of departure for interpreting aggression against minorities, look instead at whether the individual is willing to engage in self-reflection and self-criticism. Perhaps it is not how an individual deals with personal aggression after all. Among both the dismissing subjects and the entangled subjects, who could not describe themselves or their attachments with any distance, we find little evidence of self-reflection or selfcriticism. In both groups we can observe a tendency towards what the investigations in The Authoritarian Personality called "anti-intraception." With "anti-intraception" or anti-introspection we mean the disinclination to think about one's self and one's own feelings, or the resistance to a sustained, psychological self-reflection and the almost exclusive focus on practical action and effectiveness (see Adorno et al. 1969, 234-35).

It could be that precisely those individuals who do not often think about themselves and their emotions are less able to put themselves in others' shoes or sympathize with their situation. It thus becomes easier for them to tolerate aggression against minorities, including violent acts. This is, for example, the case with Frauke, whose relationship to her childhood and her mother was presented above. In the interview conducted with her about her political leanings there is very little sign that she is sorry for the victims of violent acts. On the other hand, she shows great understanding for the perpetrators and their, in her eyes, "economic motives." In this respect, one could talk of an empathy for the perpetrator, but not sympathy for the weaker, the victims of violent acts.

Probably the most appropriate approach is to utilize both interpretative variants when trying to understand how attachment is linked to aggression against minorities. The different variations of an insecure attachment representation may well be related both to irrational dealings with aggressivity, and to the inability to empathize and understand another's point of view. And both tendencies can be relevant prerequisites for the development of hostility to foreigners. There is no clear answer as to whether this is actually the case, or how precisely aggressivity relates to underdeveloped empathy, solely on the basis of our previous investigations and evaluations. It is necessary to continue working on these issues, and to include new groups of study participants - this also to check whether the connections between attachment representation and ethnocentrism we observed in the Hildesheim studies can also be found in other social contexts.

\section{Closing remarks}

By way of conclusion I would like to add some more general comments about the results of our investigations.

1. It seems clear that people have very different ways of dealing with difficulties and pain rooted in social relationships, and that these dealings also have political relevance. What appears at first glance to be a non-political variant of dealing with attachment and conflict experiences can, in fact, become politically explosive when an individual is blocked from a rational 
confrontation with his or her own history, own feelings, and own aggressivity. For this reason - among others - it is important to understand how such different patterns of dealing with attachment and conflict experiences take hold. Drawing on the work of John Bowlby and Mary Ainsworth, attachment research suggests some promising approaches to these issues. Here one assumes that the various patterns of attachment representation reflect the constellations of earlier inner-familial relationships. As children interact with their parents, they acquire ideas about their accessibility, approachability, readiness to punish, etc. They develop "working models" for relations with their parents - expectations of the relationship which regulate how they behave with their parents (on this point cf. among others Main et al. 1985). These expectations change if the underlying relationships change, if new attachment figures enter the picture, or if the parents dramatically alter how they behave with their children - whether through illness, fundamental changes in their own partnership, or ups and downs in the family's economic resources. Without such changes, the child's expectations of relationships remain relatively stabile and go on to influence the attachment representation as adult. A child who reckons with rejection or punishment in the mother-child relationship, and thus takes evasive or avoident action, will tend as an adult to "dismissing" dealings with attachment and conflict experiences.

To many sociologists, these theoretical assumptions may appear a bit too adventurous. As current debates show, many of us see "society" as primarily a society of adults who, in more or less individualized contexts, enter into more or less rational, purposeful social relations. In general, little notice is taken of the fact that these same adults might face considerable constraints on their latitude for action - not only pressing economic or social restrictions, but also early attachment experiences and their cognitive and affective representation. Socialization research could offer a framework for examining hypotheses on the long-term effects of early attachment, but it has moved to the fringes of the discipline and tends to be left to research in developmental psychology. I find this a very problematic shift, one which also hampers our understanding of social integration and disintegration at a more general level. Whoever wants to find out more about successful and unsuccessful integration processes, destructivity in social contexts, and destructivity in relation to minorities, cannot dispense, to my mind, with the "attachment biographies" of individuals and how they themselves interpret them. This insight was still self-evident in Talcott Parson's theories of society and socialization, but was lost in later developments of system theory and plays no role in other theories. The psychologically-primitive premises behind much rational choice research preclude any thought of examining the personal biography to explain whether or not an individual is willing to cooperate or show solidarity with others.

2. It is clear that analyzing an individual's attachment experiences and how he or she works through them cannot completely explain existing aggression against minorities. But nor can sociology ever offer complete explanations. What we can say perhaps is that each pattern of attachment representation opens up paths for later development - to stronger aggressivity against minorities on the one hand, or to more liberal dealings with minorities, freer from affects, on the other. There is however no automatic connection. Existing tendencies can be redirected, whether in processes of explicit moral and political socialization at home, in school, or in the university, perhaps via new contacts and relationships as adolescent, or through socialization in the context of political participation. In addition, dominant ideologies and the particular character of political culture can strengthen or relativize aggression against minorities at the individual level. Sometimes political cultures are so destructive and xenophobic that explanations drawing on socialization and attachment theory pale in significance to the predominant social influences. An example of this is German society during the National Socialist period. Here hostility to minorities belonged to the cultural givens within the framework of official political socialization. In such contexts, questions about individual differences in attachment experiences might appear inappropriate. But this does not deny their general significance for understanding the roots of violence against foreigners. 